\title{
PRESENTACIÓN
}

\section{EL CHILE DE LOS ÚLTIMOS 30 AÑOS Y EL DESAFÍO DE DEBATIR}

Cuando desde la Universidad de Chile decidimos conmemorar los 30 años del plebiscito de 1988 y el triunfo del No, la pregunta por el concepto de transición y sus significados para el Chile actual fueron una constante en los debates, conversaciones y actividades que se dieron en los diferentes campus de nuestra Casa de Estudios. Hace tres décadas nuestro país vivía un punto de inflexión en su historia al transitar desde una dictadura a un proceso de democratización que aún hoy divide las aguas al momento de debatir en torno al carácter de su legado.

Estos desafíos fueron los que animaron al Comité Editorial de la Revista Anales de la Universidad de Chile a escoger esta conmemoración como tema del volumen 15 de la séptima serie de nuestra publicación. Dado que los efectos de la dictadura y la transición abarcan todos los aspectos de la vida social y política de nuestro país, el objetivo de este número fue abordar el tema desde aristas variadas, con diversos puntos de vista y opiniones.

La primera parte de este volumen está dedicada al concepto mismo de la transición. Qué es la transición y cuándo comienza y cuándo termina son algunas de las preguntas que guiaron a los autores en estos artículos. Abre la discusión una de las integrantes del Comité Editorial de la Revista y voz autorizada para hablar de la postdictadura.

Sofía Correa Sutil reflexiona sobre las negociaciones que se dieron entre la dictadura y la oposición en torno al plebiscito, estableciendo la base de lo que luego sería la forma de hacer política durante la transición. La autora hace una revisión de los acontecimientos más significativos de los últimos años de la dictadura y los primeros de la democracia, haciendo hincapié en el desarrollo de las secretas conversaciones entre ambos bandos y la paulatina e irreversible aceptación de la Constitución de 1980 por parte de los partidos de la Concertación, lo que marcaría las siguientes décadas. Correa establece, finalmente, que la transición habría terminado cuando los velos de silencio que rodearon este proceso fueron retirados.

Continúa el debate la académica de la Facultad de Filosofía y Humanidades de la Universidad de Chile, Azun Candina Polomer, quien ante la pregunta por los márgenes de la transición plantea que esta habría comenzado en 1983, año en que se profundizan los efectos de la crisis económica del '82 en un contexto de amplias manifestaciones sociales; y terminaría en 1989, para luego dar paso a lo que ella llama instalación democrática. Así como Correa, Candina propone que la transición tiene directa relación con las negociaciones entre el régimen y la oposición, pero a 
la vez advierte que el concepto también tiene relación con sensibilidades y estados de ánimo del país, encarnados en las protestas sociales de mediados de la década.

Genaro Arriagada Herrera, ex ministro Secretario General de Gobierno y testigo de primera línea del fin de la dictadura e inicios de la democracia, da cuenta de las divisiones de la sociedad chilena en ese periodo histórico y de los diferentes proyectos país que en ese momento se contraponían. Arriagada hace una evaluación positiva de los aspectos más relevantes de los gobiernos de la Concertación, estableciendo un contrapunto con otras experiencias transicionales en América Latina y Europa.

Pero en 2018 no solo se cumplieron tres décadas del plebiscito, sino también 20 años de la detención de Pinochet en Londres. A raíz de este hito, el académico de la Facultad de Derecho Juan Pablo Mañalich Raffo da cuenta del estado del Poder Judicial durante la transición y de los impedimentos esgrimidos por este en casos de violaciones a los derechos humanos. Acuñando el concepto de "trivialización del terror", nos recuerda las razones de por qué la justicia transicional no puede ser relegada al mundo jurídico exclusivamente.

Cierran esta primera parte las palabras del sociólogo Tomás Moulian Emparanza, quien realiza una relectura de la transición a partir de los postulados de su obra más importante, Chile actual: anatomía de un mito. El liberalismo extremo, dice Moulian, punta de lanza del proyecto de la dictadura, se mantiene y profundiza durante los gobiernos de la Concertación, trayendo de la mano una mercantilización de la cultura, reemplazándola por "la pasión por el consumo y el dinero".

Como una pausa de contingencia entre las reflexiones planteadas en los artículos aparece luego la mesa de conversación "A 30 años del triunfo del No: reflexión y debate en torno al Chile de la transición", la que se llevó a cabo el 5 de octubre de 2018 en el Salón de Honor de la Universidad de Chile. Con la idea de hacer un recuento y un análisis crítico de las últimas tres décadas participaron de ella el ex Presidente Ricardo Lagos Escobar, la ex senadora Carmen Frei Ruiz-Tagle, el alcalde de la comuna de Recoleta, Daniel Jadue Jadue; el Premio Nacional de Humanidades y Ciencias Sociales, Manuel Antonio Garretón Merino; el académico de la Universidad de Chile y presidente de la Fundación Nodo XXI, Carlos Ruiz Encina; y Karla Toro Inostroza, presidenta de la FECH.

La segunda parte de este número amplía la mirada e invita a los autores a abarcar de forma compleja las diferentes áreas de la vida cotidiana que fueron afectadas por la transición. Desde la cultura y la literatura, el profesor Grínor Rojo de la Rosa argumenta que el despojo material del pueblo durante la dictadura vivió también un correlato cultural, cuyo objetivo era establecer un sistema de clase profundamente desigual en términos económicos, educacionales y culturales. A través de un agudo análisis de los diferentes campos culturales, el autor da cuenta de la destrucción 
sistemática de parte de la dictadura de toda iniciativa que buscara democratizar el conocimiento y la cultura (con la editorial Quimantú como ejemplo más claro), así como también de las diferentes trincheras de resistencia que fueron brotando durante la dictadura y luego también en la transición.

Por su parte, el profesor Claudio Nash Rojas, coordinador académico de la Cátedra de Derechos Humanos de la Vicerrectoría de Extensión y Comunicaciones de nuestra Casa de Estudios, aborda las deudas en esta materia por parte de los gobiernos de la Concertación. Haciendo un paralelo con los estándares internacionales desarrollados en Latinoamérica, Nash sistematiza los avances, pero también los profundos pendientes de Chile en verdad, justicia, reparación, memoria y reformas institucionales, los que han contribuido a mantener la impunidad de quienes participaron en las violaciones a los derechos humanos durante la dictadura.

Con un poderoso guiño a la contingencia actual, Fernando Pairican Padilla aborda las historias del movimiento mapuche durante los gobiernos de la Concertación y sus dos líneas de respuesta: social y represiva. A partir de esa dualidad el autor detalla minuciosamente la realidad indígena de América Latina y cómo los gobiernos de la postdictadura chilena intentaron despojar al movimiento mapuche de su aspecto político, limitándolo a las arenas cultural y económica, en lo que él llama las políticas del multiculturalismo. Pairican se explaya en las formas de reacción que ha adoptado el movimiento mapuche, que se debate entre apoyar la idea de un Estado plurinacional y exigir la autodeterminación.

A continuación, el debate se traslada al campo de la educación. De la mano de los académicos de la Universidad de Chile Claudio Gutiérrez Gallardo, Mercedes López Nitsche y Carlos Ruiz-Schneider, el artículo hace un recorrido por los principales cambios sufridos por la educación superior durante los años posteriores a la dictadura. Los autores se detienen especialmente en la nueva conceptualización de la educación como "un problema de optimización económica, institucional y sociológica", ante lo cual el Estado ha enfocado sus políticas del área en apreciar el conocimiento como mercancía intercambiable y en asumir un rol de evaluador del desempeño bajo el estandarte de la calidad.

Desde el periodismo, en tanto, la Premio Nacional María Olivia Mönckeberg Pardo nos relata la historia de privatizaciones de la dictadura y de la concentración de la riqueza que tuvo como consecuencia. La periodista se centra en el caso Soquimich y la red de influencias y corrupción que formó a su alero Julio Ponce Lerou para el financiamiento ilegal de la política chilena, evidenciando en el proceso la falta interés de los gobiernos de la transición por cambiar el escenario económico impuesto por la dictadura.

Federico Galende, académico de la Facultad de Artes, reflexiona en su artículo sobre el concepto del no como acción y decisión, definiendo a la transición como 
"producto de un no traicionado por la afirmación de una clase política". Desde ese punto de vista analiza las formas de representación de ese periodo, concluyendo que la política de la época conduce a las esferas del arte y la crítica hacia un grado de cero representación, rompiendo así con lo que se venía trabajando durante el siglo XX.

Siguiendo en las líneas de la representación, Alejandra Castillo Vega desarrolla la noción de las políticas de la presencia en la participación política femenina, en especial durante el primer gobierno de Michelle Bachelet. Ante el anuncio de un gabinete paritario y la incorporación femenina en la primera línea política, Castillo contrapone el concepto de la excelencia como forma de justificación de esta inclusión, lo que vuelve a reducir el círculo de quiénes pueden acceder a ese mundo.

Por su parte, Alejandra Farías Köhnenkampf titula su artículo con la desafiante pregunta de si la transición es en realidad el Chile que Augusto Pinochet soñó en sus años en el poder. Para sostener esta potencial afirmación la autora hace un análisis del uso de los medios de comunicación y los anuncios callejeros como plataforma para consolidar la producción discursiva elaborada por los sectores económicos dominantes durante la dictadura, develando cómo la transición dejó morir la prensa opositora en pos de sostener el modelo neoliberal.

Las teatralidades y performatividades de la transición son el tópico de Mauricio Barría Jara, quien desde el ámbito teatral repasa los principales hitos de esta disciplina en la primera década de democracia. Barría plantea la idea de “escenas sintomáticas" para dar cuenta del ánimo y la realidad de la transición, tres momentos entre los '90 y los 2000 que abordan los claros y oscuros fruto de la herencia dictatorial.

Cierra este volumen un dossier histórico a cargo de la Doctora en Historia Azun Candina Polomer, en el que a través de documentos políticos clave se repasan momentos trascendentales de la transición. Los informes Rettig y Valech, discursos de Patricio Aylwin, el reconocimiento de Pinochet a la modificación de algunos artículos de la Constitución, el "nunca más" del general Juan Emilio Cheyre y las disputas entre "autocomplacientes" y "autoflagelantes" dentro de la Concertación nos dibujan un tiempo que prometía ser de alegría, pero que en el camino fue develando que se trataba de una alegría supeditada tanto a la política de los acuerdos como a los lineamientos económicos y políticos heredados de la dictadura cívicomilitar.

Faride Zeran Chelech Directora de Anales de la Universidad de Chile Vicerrectora de Extensión y Comunicaciones Premio Nacional de Periodismo 2007 